\title{
ДОРСОПАТИИ: АКТУАЛЬНОСТЬ ПРОФИЛАКТИЧЕСКИХ ОСМОТРОВ ДЛЯ РАННЕЙ ДИАГНОСТИКИ, ВЫЯВЛЕНИЯ ФАКТОРОВ РИСКА И КОМОРБИДНЫХ ЗАБОЛЕВАНИЙ
}

\author{
И. Н. Денисов ${ }^{1}$, Т. В. Заугольникова ${ }^{1}$, Т. С. Попова ${ }^{1,2}$, Т. Е. Морозова \\ ${ }^{1}$ Кафедра общей врачебной практики, \\ Первый Московский государственный медицинский университет имени И. М. Сеченова (Сеченовский университет), Москва \\ 20ОО Клиника «Первый доктор», Москва
}

Лечебно-профилактические мероприятия по ранней диагностике дорсопатий являются актуальной задачей врачей первичного звена здравоохранения. Это обусловлено тем, что сочетание дорсопатий с другими хроническими неинфекционными заболеваниями (ХНИЗ) фрормирует коморбидность, которая неблагоприятно влияет на их течение и исходы, увеличивает обращаемость населения за медицинской помощью, ухудшает качество жизни пациентов. Целью работы было определить значение профилактических осмотров в диагностике дорсопатий, сопутствующих ХНИЗ, и выявлении факторов риска (ФР). Проведен ретроспективный анализ базы данных амбулаторных карт пациентов сельской амбулатории Тверской области за 2015-2017 гг. Исследовали распространенность дорсопатий и ФР ХНИЗ. При статистической обработке применяли точный критерий Фишера и коэффициент ранговой корреляции Спирмена (KPKC). Было показано, что дорсопатия чаще всего сочеталась с артериальной гипертензией и заболеваниями желудочно-кишечного тракта, имеет сильную корреляционную связь с сопутствующими ХНИЗ (KPКС = 0,506); возрастом (KPKC = 0,383); более слабую с гиподинамией (KPKC = 0,146) и слабую с видом деятельности пациента (интеллектуальным или физическим трудом) (KPKC = 0,07). Профилактические осмотры улучшают диагностику дорсопатии - число выявляемых случаев заболевания растет с увеличением количества обследуемых в рамках профилактических осмотров пациентов. Таким образом, необходимо шире проводить профилактические осмотры для работающего населения с целью раннего выявления дорсопатии и эффективной ее профилактики.

Ключевые слова: профилактические осмотры, дорсопатия, факторы риска, коморбидность, жители села

Благодарности: главному врачу Мокшинской амбулатории Конаковского района Тверской области Л. В. Тяжеловой за содействие при сборе материала для статьи и предоставление помещения для работы с документацией.

$\bowtie$ Для корреспонденции: Татьяна Сергеевна Попова Северный бульвар, д. 7Б, г. Москва, 127566; bluesfinks@mail.ru

Статья получена: 06.09.18 Статья принята к печати: 05.11.18

DOI: $10.24075 /$ vrgmu.2018.065

\section{DORSOPATHIES: ROUTINE CHECKUPS AS A PROCEDURE NECESSARY FOR EARLY DIAGNOSTICS, RISK FACTORS AND COMORBIDITIES IDENTIFICATION}

\author{
Denisov $\mathbb{I N}^{1}$, Zaugolnikova TV ${ }^{1}$, Popova TS ${ }^{1,2} \otimes$, Morozova TE ${ }^{1}$ \\ 1 Department of General practice, \\ Sechenov First Moscow State Medical University (Sechenov University), Moscow \\ ${ }^{2}$ First Doctor clinic, Moscow
}

Early detection of dorsopathies is an urgent task for primary care physicians, since such conditions can combine with other chronic noncommunicable diseases (NCD) and adversely affect the course all comorbidities, consequently disimproving the quality of life of patients and increasing the frequency of their requests for medical assistance. This study aimed to determine the value of routine checkups in the context of detection of dorsopathies, NCD, and identification of risk factors (RF). We have retrospectively analyzed the patient records database of a rural outpatient clinic in the Tver region (years 2015 to 2017 ). The prevalence of dorsopathies and NCD RF were the subjects investigated. Fisher's exact test and Spearman's rank correlation coefficient (SRCC) were applied for the purposes of statistical processing of the results. We discovered that dorsopathy most often was a comorbidity to arterial hypertension and gastrointestinal tract diseases; it was strongly related to the NCD (SRCC = 0.506), age (SRCC $=0.383$ ), slightly less so - to hypodynamia $(S R C C=0.146)$, type of the patient's occupation (intellectual or physical labor) (SRCC $=0.07$ ). Routine checkups improve the rate of detection of dorsopathy: the more patients undergo such examinations, the more cases of dorsopathy are diagnosed. Thus, it is necessary to increase the number of working people attending the checkups in order to detect dorsopathies early and prevent them effectively.

Keywords: preventive medical examination, dorsopathy, risk factors, comorbidity, village resident.

Acknowledgment: authors of the study express their gratitude to L.V. Tyazhelova, head physician of the Mokshino outpatient clinic (Konakovo district, Tver region) for assistance in collecting material for the article and providing a room to work with the papers

$\triangle$ Correspondence should be addressed: Tatyana S. Popova Severny Boulevard, 7B, Moscow, 127566; bluesfinks@mail.ru

Received: 06.09.18 Accepted: 05.11.18

DOI: $10.24075 /$ brsmu.2018.065 
Профилактика и лечение хронических неинфекционных заболеваний (ХНИЗ) обозначены Всемирной организацией здравоохранения (ВОЗ) как приоритетный проект второго десятилетия XXI в., направленный на улучшение качества жизни населения мира [1]. Профилактическая работа проводится по двум основным направлениям: формирование здорового образа жизни и ранняя диагностика ХНИЗ, выявление факторов риска (ФР) ХНИЗ с последующей своевременной коррекцией. Второе направление осуществляется в рамках системы здравоохранения. Особенная роль возлагается на врачей первичного звена: врачей-терапевтов участковых, врачей общей практики (семейных врачей), профилактическая работа которых должна занимать не менее 30-40\% их рабочего времени [2].

Болезни костно-мышечной системы и соединительной ткани (БКМС) широко распространены и включают более 150 различных заболеваний и синдромов, обычно связанных с болью и нарушением работы костномышечного аппарата. В развитых странах эти заболевания являются одной из самых частых причин инвалидности в силу старения демографических групп, проживающих на наиболее густонаселенных территориях. ВОЗ в 2000 г. объявила Международную декаду костно-суставных заболеваний (The Bone and Joint Decade 2000-2010), призванную привлечь внимание общественности всех стран мира к существующей проблеме. В рамках декады большое значение придавалось изучению медико-социальной и экономической нагрузки на общество заболеваний опорно-двигательного аппарата, всестороннему осмыслению ФР, которые оказывают влияние на формирование костно-мышечной патологии, ее прогрессирование, и наличию сопутствующей патологии (коморбидности) [3]. По данным, опубликованным в 2016 г., каждый третий житель Европы, жалующийся на боли в мышцах, костях и суставах, отмечает ограничение движений. Различия по этому показателю между странами составляют от 18\% в Ирландии до 46\% в Хорватии [4]. Боль в области поясницы является наиболее распространенной жалобой, о которой сообщают 11\% всех пациентов. В два раза чаще боль встречается у пожилых людей (в возрасте 55 лет и старше). Чаще у женщин (37\%), чем у мужчин (27\%) [4].

В связи с демографическими изменениями (старение населения) и связанными с образом жизни ФР ХНИЗ прогнозируется дальнейшее увеличение роста этой группы патологий. БКМС часто сочетаются с заболеваниями сердечно-сосудистой системы. Сложность лечения больных с такой коморбидностью составляет одну из причин повышенной летальности этих пациентов [5, 6].

Целью работы было определить значение профилактических осмотров в ранней диагностике дорсопатии, выявлении сопутствующих ХНИЗ и их ФР.

\section{МАТЕРИАЛЫ И МЕТОДЬ}

Объектом исследования стали отчетные формы Мокшинской сельской амбулатории двух участков врачей общей практики Конаковского района Тверской области: основные показатели 2011-2016 гг.: годовые отчеты (формы 30, 12), «Медицинские карты амбулаторного больного» (УФ №025/y); «Контрольные карты диспансерного наблюдения» (УФ № 030/y); «Карты учета дополнительной диспансеризации работающего гражданина» (УФ № 131/y-ДД-10) и другие учетные формы профилактических и дополнительных диспансеризаций работающих граждан. Был выполнен ретроспективный анализ базы данных за 2015-2017 гг. Для анализа возрастных особенностей формирования коморбидности у пациентов с дорсопатиями из общей базы данных были отобраны 1203 карты больных с диагнозом дорсопатии. Критерии включения: мужчины и женщины в возрасте от 18 лет и старше, наличие диагноза дорсопатии, подписание информированного согласия.

Критерии исключения: возраст до 18 лет, отсутствие установленного ранее диагноза дорсопатии. У этих больных анализировали следующие показатели: время появления первых жалоб, дата постановки диагноза дорсопатии, наличие ФР и присутствие сопутствующих заболеваний.

Протокол исследования № 10-16 от 9 ноября 2016 г. одобрен местным комитетом по этике Первого МГМУ им. И. М. Сеченова. Деление на возрастные группы и категории проводили согласно классификации ВОЗ: молодой (18-44 года), средний (44-60 лет), пожилой (60-75 лет), старческий (75-90 лет), долгожители (90+ лет).

Диагностические критерии ФР и патологических состояний и заболеваний устанавливали согласно критериям, рекомендованным Приложением № 2 Приказа Минздрава России от 3 декабря 2012 г. № 1006н.

\section{Статистическая обработка}

При планировании работы величину выборки пациентов Мокшинской амбулатории определяли при помощи модулей Sample size программ COMPARE 23.85 и DESCRIBE 3.18 пакета WinPEPIC) 11.65 (автор и правообладатель программ JH Abramson). Статистическую обработку полученных результатов проводили с использованием точного критерия Фишера. Для изучения связи между дорсопатией и ФР, другими ХНИЗ использовали КРКС. Пороговое значение статистической значимости составляло 5\%.

\section{РЕЗУЛЬТАТЫ ИСЛЕДОВАНИЯ}

C увеличением количества обследованных на профилактических осмотрах увеличивается выявление

Таблица. Количественные показатели профилактических осмотров взрослого населения и выявленных случаев дорсопатии в Мокшинской амбулатории в период с 2011 по 2016 г.

\begin{tabular}{|l|c|c|c|c|c|c|}
\hline \multirow{2}{*}{ Показатели } & \multicolumn{5}{c|}{ Период отчетности, год } \\
\cline { 2 - 8 } & 2011 & 2012 & 2013 & 2014 & 2015 & 2016 \\
\hline Численность прикрепленного населения, чел. & 2237 & 2216 & 2217 & 2206 & 2217 & 2202 \\
\hline Количество посещений амбулатории, раз & 6122 & 6640 & 5587 & 5963 & 6784 & 5963 \\
\hline Количество профилактических осмотров, раз & 1033 & 1128 & 1033 & 1493 & 1776 & 1493 \\
\hline Выявленные случаи дорсопатии, чел. & 257 & 253 & 281 & 299 & 327 & 347 \\
\hline $\begin{array}{l}\text { Количество лиц с дорсопатией, находящихся под } \\
\text { диспансерным наблюдением на конец отчетного года, чел. }\end{array}$ & 257 & 263 & 280 & 299 & 324 & 345 \\
\hline
\end{tabular}


дорсопатии даже при уменьшении активных посещений амбулатории и количества прикрепленных к амбулатории пациентов (на 2,6\% (159 человек) и на 1,6\% (35 человек) соответственно) (таблица; рис. 1 и 2).

Распространенность ФР ХНИЗ с учетом гендерного деления у 1203 жителей сельской местности (540 мужчин и 663 женщины) представлена на рис. 3. Наиболее распространенными ФР у мужчин были курение (73\%) и гиперхолестеринемия (ГХС) (17,3\%). Преобладающим ФР у женщин была избыточная масса тела (39,8\%).

По распространенности артериальная гипертония (АГ) заняла 1-е место: 516 пациентов (42,9\% из всех обследованных, 42 892,76 случаев на 100000 человек). Из них 207 мужчин (38,3\% из всех обследованных мужчин) и 309 женщин (46,6\% из всех обследованных женщин). Гендерные различия статистически значимы ( $p=0,004)$. Дорсопатия по распространенности заняла 2-е место. Эта патология диагностирована у 347 пациентов $(28,8 \%$ от общего числа обследуемых) и составила 28 844,56 случаев на 100000 человек. Из них 147 мужчин (27,2\% из всех обследованных мужчин) и 200 женщин (30,2\% из всех обследованных женщин). Гендерные различия статистически незначительны ( $p=0,277)$. На 3-м месте по распространенности были заболевания желудочнокишечного тракта (ЗЖККТ) (кроме язвенной болезни желудка и двенадцатиперстной кишки): 141 пациент (11,7\% из всех обследованных, 11 720,69 случаев на 100000 человек). Из них 44 мужчины (8,1\% из всех обследованных мужчин) и 97 женщин (14,6\% из всех обследованных женщин).
Гендерные различия статистически значимы $(\rho=0,001)$ (рис. 4). В 2016 г. среди молодых пациентов (18-44 лет) дорсопатия зарегистрирована у 83 человек (23,9\% из всех больных дорсопатией); у пациентов среднего возраста (44-60 лет) - 127 случаев (36,6\%); пожилого возраста (60-75 лет) и старше - 137 случаев (39,5\%).

В разные годы с 2011 по 2016 г. 99,1-100\% пациентов с установленным диагнозом «дорсопатия» состояли на диспансерном учете у врача общей практики Мокшинской амбулатории (см. таблицу).

У $31,7 \%$ пациентов дорсопатия встречалась в виде единственного имеющегося заболевания; в сочетании с одним заболеванием - 28,5\%; двумя и более заболеваниями - 40\% (от общего числа пациентов с дорсопатией).

Чаще всего дорсопатия сочеталась с АГ - 191 случай (55,0\% из всех больных дорсопатией), ЗЖККТ (кроме язвенной болезни желудка и двенадцатиперстной кишки) 67 случаев (19,3\%). Реже сопутствующим заболеванием были ишемическая болезнь сердца (ИБС) - 33 (9,5\% от всех больных дорсопатией), ожирение - 27 (7,8\%), сахарный диабет (СД) - 20 (5,8\%), язвенная болезнь желудка и двенадцатиперстной кишки - 17 (4,9\%), хронические заболевания органов дыхания (ХЗОД) - 15 (4,3\%). При всех перечисленных сопутствующих заболеваниях, кроме ИБС, дорсопатией преимущественно болеют женщины. У пациентов с дорсопатией в сочетании с СД или ожирением количество болеющих женщин значительно превышает число мужчин: 2,7\% мужчин и 8,0\% женщин (при наличии

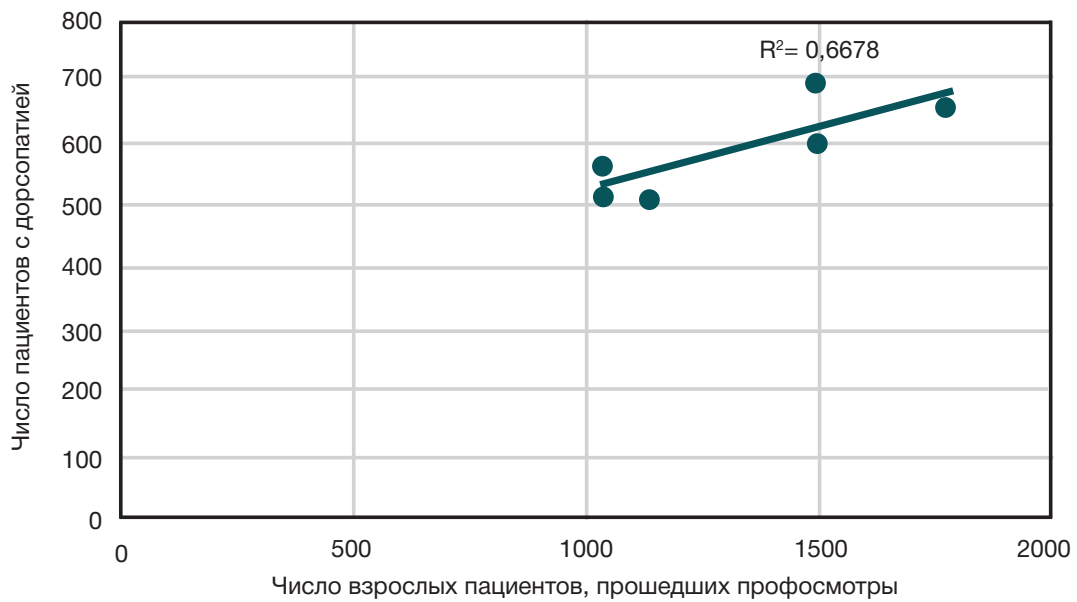

Рис. 1. Увеличение числа пациентов с дорсопатией в зависимости от увеличения пациентов, обследуемых в ходе просоосмотров в $2011-2016$ гг.

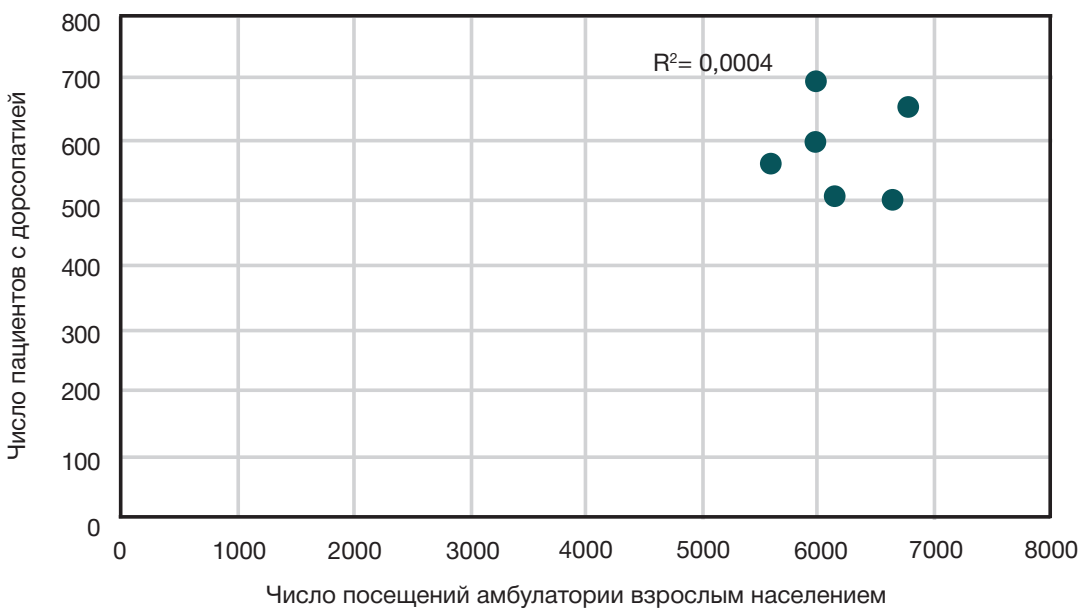

Рис. 2. Точечная диаграмма распределения числа пациентов с дорсопатией и количеством активных посещений Мокшинской амбулатории взрослыми пациентами в 2011-2016 гг. 
СД) и 1,4\% мужчин и 12,5\% женщин (при сопутствующем ожирении). Сочетание дорсопатии и ИБС распространено в равной степени среди мужчин и женщин (9,5\%).

Значения КРКС между дорсопатией и ФР ХНИЗ в исследуемой популяции на селе в 2016 г. представлены на рис. 5. Наиболее сильная прямая корреляционная связь прослеживается между дорсопатией и наличием у пациента сопутствующих ХНИЗ (КРКС = 0,506); дорсопатией и возрастом (KPKC = 0,383). Более слабую прямую корреляционную связь дорсопатия имеет с гиподинамией $(\mathrm{KPKC}=0,146)$ и еще меньше она зависит от вида деятельности пациента (интеллектуального или фризического труда) (КРКС = 0,07). Сильную обратную корреляционную связь дорсопатия имеет с отсутствием сопутствующей патологии (KPKC $=-0,406) ;$ слабую обратную корреляционную связь со злоупотреблением алкоголя (KPKC $=-0,006)$. В исследуемой выборке пациентов с дорсопатией (347 пациентов) гендерные различия не были статистически значимыми.

\section{ОБСУЖДЕНИЕ РЕЗУЛЬТАТОВ}

В Российской Федерации (РФ) в 2016 г. по классу БКМС (по МКБ-10: М00-М99), в которые входит дорсопатия, была зарегистрирована заболеваемость в 2953,2 случаях на 100000 человек (в общем по стране) и в 9402,5 случаях на 100000 человек сельского населения. В Центральном федеральном округе этот показатель составил 8707,4 случая на 100000 человек сельского населения. По Тверской области в 2016 г. - 11 179,5 случаев на 100000 человек сельского населения [7]. Таким образом, данные по дорсопатии в Мокшинской сельской амбулатории (28 844,56 случаев на 100000 человек) в 2016 г. выше в 3,1 раза среднестатистических показателей по классу БКМС (куда входит дорсопатия), выявленных в РФ среди сельского населения, и в 3,3 раза выше этого показателя по Центральному федеральному округу среди сельского населения. Численность сельских жителей старше трудоспособного возраста в РФ с 2004 по 2013 г. возросла на 2,5\% и продолжает увеличиваться [8]. Тверская область входит в перечень субъектов РФ с наибольшей долей (в \%) лиц старше трудоспособного возраста в структуре сельского населения и занимает 2-е место в Центральном федеральном округе по этому показателю (на 1 января 2016 г.): 32,4\% [9]. Высокую частоту дорсопатии в исследуемой популяции можно объяснить старением населения (по нашим данным, наиболее сильная прямая корреляционная связь наблюдается между дорсопатией и возрастом (KРКС = 0,383) (рис. 4).

Статистические данные Мокшинской амбулатории по дорсопатии (28 844,56 случаев на 100000 человек) в 2,6 раз выше, чем в среднем по Тверской области по классу

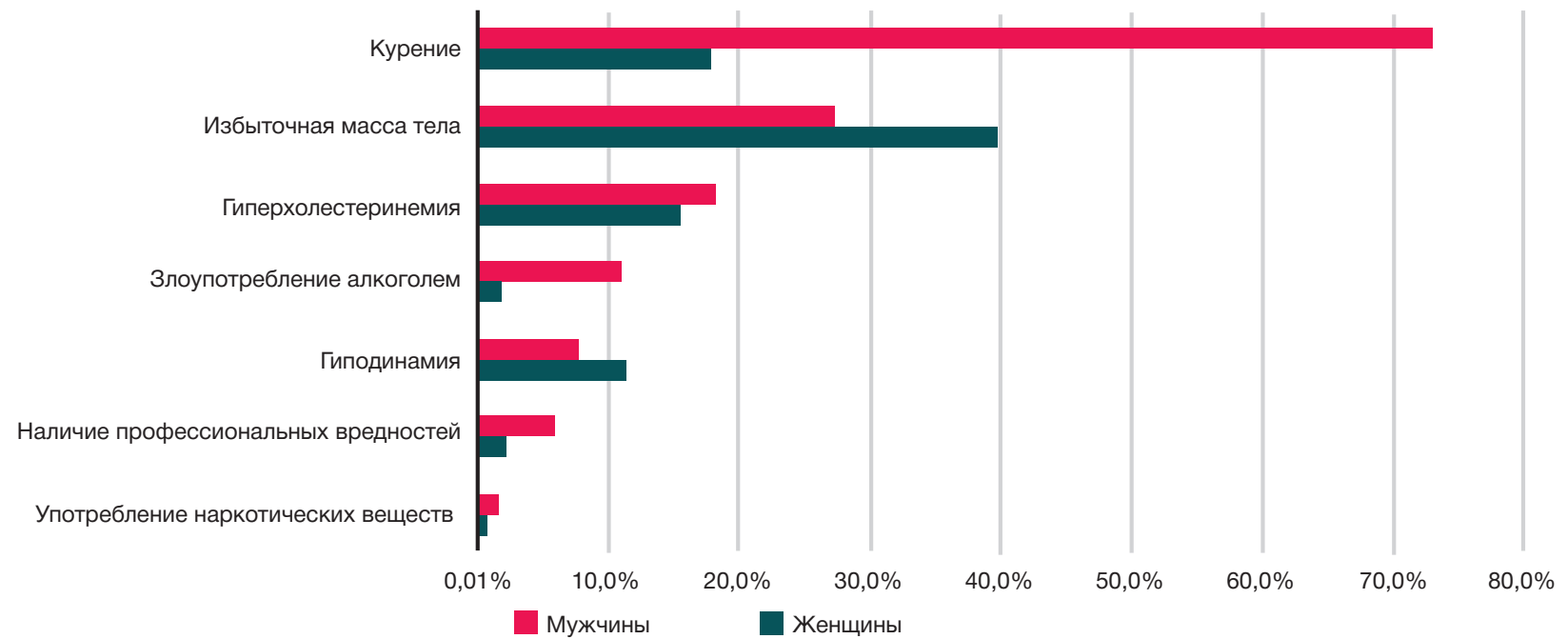

Рис. 3. Распространенность ФР с учетом гендерных признаков у 1203 жителей сельской местности. За $100 \%$ взято 540 мужчин и 663 женщины. гД гиподинамия, ГХС — гиперхолестеринемия, ЗА - злоупотребление алкоголем, ИМТ — избыточная масса тела

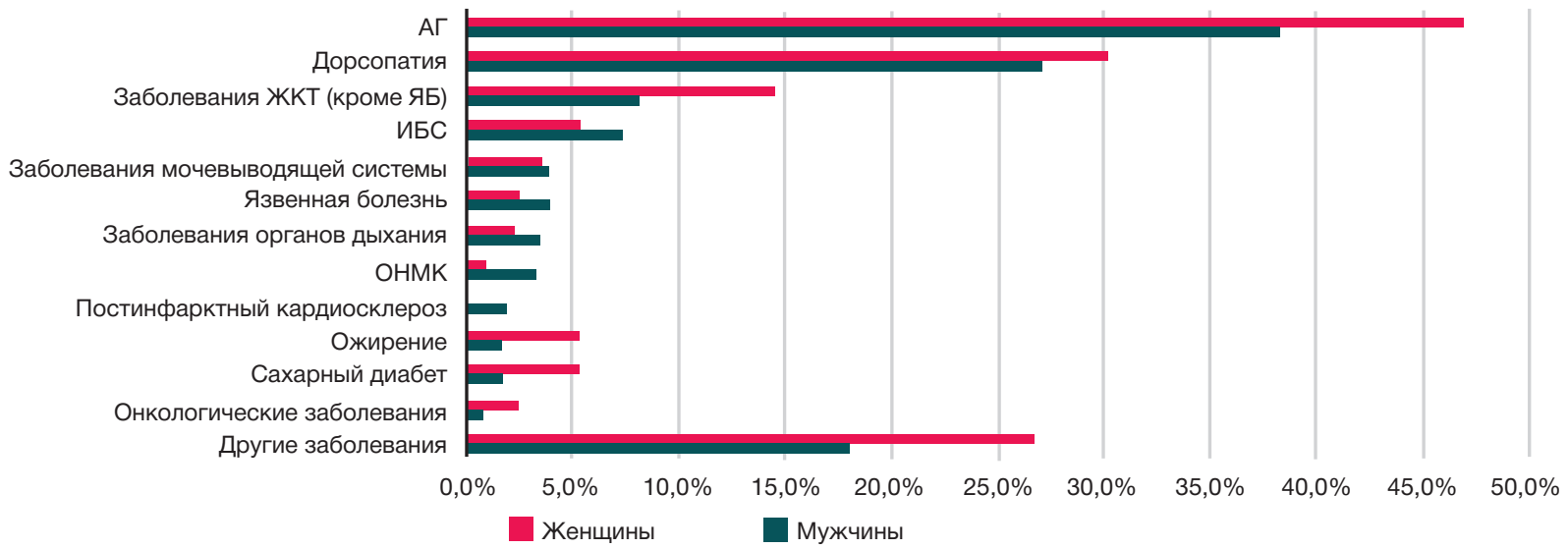

Рис. 4. Структура ХНИЗ у 1203 жителей сельской местности. За 100\% взято 540 мужчин и 663 женщины. АГ - артериальная гипертензия, ЗЖКК (кроме ЯБ) - заболевания желудочно-кишечного тракта (кроме ЯБ), ИБС - ишемическая болезнь сердца, ОНМК - острое нарушение мозгового кровообращения, ПИКС - постинфарктный кардиосклероз, СД - сахарный диабет, ХЗМС - хронические заболевания мочевыводящей системы, хзОД - хронические заболевания органов дыхания, яБ — язвенная болезнь 


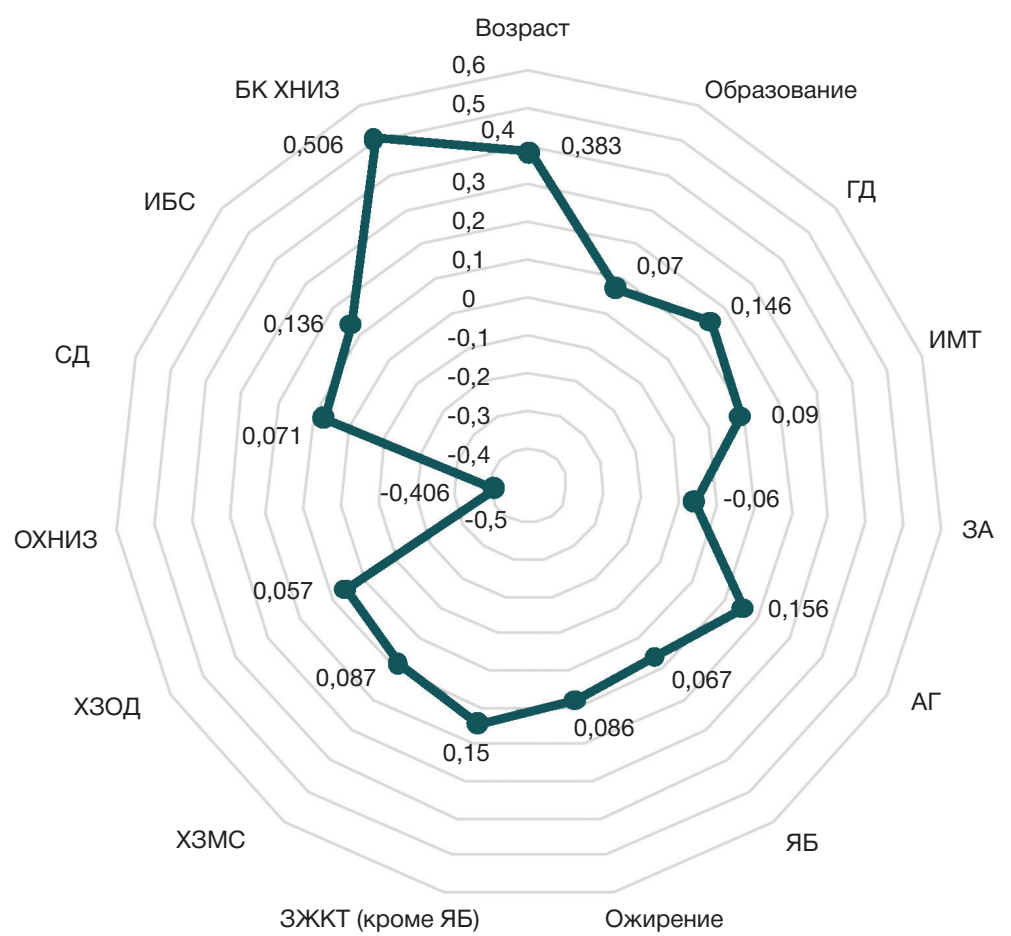

Рис. 5. Значения коэффициентов ранговой корреляции Спирмана между дорсопатией и другими факторами в исследуемой популяции сельских жителей. АГ - артериальная гипертензия, ГД - гиподинамия, ЗА - злоупотребление алкоголем, ЗЖКТ (кроме ЯБ) - заболевания желудочно-кишечного тракта (кроме ЯБ), ИБС - ишемическая болезнь сердца, ИМТ - избыточная масса тела, БК ХНИЗ - большое количество хронических неинфекционных заболеваний, ОХНИЗ - отсутствие хронических неинфекционных заболеваний, СД - сахарный диабет, ХЗМС - хронические заболевания мочевыводящей системы, ХЗОД — хронические заболевания органов дыхания, ЯБ — язвенная болезнь

БКМС среди сельского населения, по данным Росстата за 2016 г. [7]. Такие показатели по дорсопатии нуждаются в дальнейшем исследовании этого заболевания и выявлении причин его распространения в данной популяции.

На международном уровне нет единого общепринятого определения и качества оценки дорсопатии. Чаще всего она входит в состав исследований по хронической боли опорно-двигательного аппарата (ХБОДА) - боль длительностью не менее трех месяцев в течение прошедшего года. Самыми большими тиражируемыми кросс-секционными исследованиями, использующими идентичные вопросы для изучения распространенности ХБОДА, являются исследования, проведенные в Норвегии среди взрослого населения в возрасте 20 лет и старше в 1995-1997 гг. $(H=92,936)$ и 2006-2008 гг. $(H=94,194)$ : распространенность ХБОДА значительно увеличилась в течение 11 лет, была выше у женщин пожилого возраста (50 лет и старше), у «курильщиков» и пациентов с ожирением. Наиболее заметный рост распространенности ХБОДА в течение 11 лет был среди участников в возрасте 20-29 лет. Рост ХБОДА был статистически значим среди обоих полов и объяснялся у молодых пациентов распространением гиподинамии за счет использования компьютеров и мобильных телесонов [10]. Данные этого исследования совпадают с нашими результатами по Мокшинской сельской амбулатории в 2016 г.

В Республике Беларусь в 2011 г. распространенность дорсопатии составила 8008,5 \pm 4804,6 случаев на 100000 человек (в зависимости от региона) [11]. Даже при максимальном показателе распространенности дорсопатии в Беларусии (12813,1 случай на 100000 человек) данные Мокшинской амбулатории за 2011 г. в 1,7 раз больше (21366,34 случая на 100000 человек).

Интересна работа американских ученых по определению тензора структуры трабекулярной костной ткани [12]. Исследование доказывает связь БКМС с гиподинамией (в нашей популяции КPKC между двумя этими показателями равен 0,146). Ссылаясь на закон Вольфа, экспериментальным методом авторы доказали, что для правильного формирования костной структуры важно наличие умеренной нагрузки на костно-мышечный аппарат.

Для проведения вторичной профилактики дорсопатии рекомендуют организовывать школы для пациентов с болью в спине [13]. На занятиях необходимо объяснять важность умеренной двигательной активности, максимального исключения ФР ХНИЗ $[14,15]$, лечения сопутствующей патологии и физиотерапевтического лечения. Такие школы активно работают во многих странах, например в Австралии [16].

\section{ВЫВОДЫ}

В структуре ХНИЗ жителей сельской местности Тверской области дорсопатия занимает 2-е место как у пациентов занимающихся тяжелым физическим трудом, так и у людей умственного труда. Результаты исследования продемонстрировали, что просилактические осмотры увеличивают выявляемость дорсопатии и ФР ХНИЗ даже при уменьшении числа посещений амбулатории и являются эффективным инструментом для проведения первичной и вторичной профилактики дорсопатии.

Дорсопатии имеют сильную корреляционную связь с сопутствующими ХНИЗ, возрастом; более слабую с гиподинамией и слабую - с видом деятельности пациента (интеллектуальным или физическим трудом). Среди пациентов с дорсопатией в сочетании с СД или ожирением количество болеющих женщин значительно превышает количество мужчин. Сочетание дорсопатии с ИБС распространено в равной степени среди мужчин и женщин. 
При ведении пациентов с дорсопатией на сельском врачебном участке врачам общей практики рекомендовано организовывать школы для пациентов с болью в спине, В которых нужно объяснять пациентам необходимость умеренной двигательной активности, исключения ФР ХНИЗ, лечения коморбидных заболеваний; важность физиотерапевтического лечения. В образовательные программы врачей общей практики должны быть включены вопросы ведения пожилых пациентов, проживающих в сельской местности, и влияния малоподвижного образа жизни, связанного с компьютеризацией общества, на развитие дорсопатии.

\section{Литература}

1. Здоровье-2020: основы европейской политики и стратегия для XXI века. Доступно по ссылке: www.euro.who.int/_data/ assets/pdf_file/0017/215432/Health2020-Long-Rus.pdf.

2. Бойцов С. А., Чучалин А. Г., редакторы. Просилактика хронических неинфекционных заболеваний. Рекомендации. M., 2013; 136

3. WHO Scientific Group. Burden of musculoskeletal conditions at the start of the new millennium. Technical Report Series. Genove, Switzerland: World Health Organization; 2003: 1-218. Available from: http://www.who.int/iris/handle/10665/ 42721.

4. EUMUSC.NET. Musculoskeletal Health in Europe. Available from: http://www.eumusc.net/myUploadData/files/30\%20August\% 20Final\%20draft\%20report.pdf [accessed 10 April 2016].

5. Мазуров В. И., Лесняк О. М., редакторы. Остеоартрит. Ревматология. Фармакотерапия без ошибок: руководство для врачей. М.: Е-ното, 2017; с. 51-78.

6. Николаев Ю. А., Митрофанов И. М., Поляков В. Я. и др. Артериальная гипертензия, связанная с соматической патологией, в современной практике внутренних заболеваний. Здоровье. 2014; 6 (1): 94-8.

7. Здравоохранение в России. 2017: Статистический сборник Росстат. М., 2017; 170.

8. Шляфер С. И. Оценка состояния здоровья сельского населения старше трудоспособного возраста в Российской Федерации. Проблемы социальной гигиены, здравоохранения и истории медицины. 2014; (5): 13-19.

9. Численность населения Российской Федерации по полу и возрасту на 1 января 2017 г. Бюллетень. Доступно по ссылке: http://www.gks.ru/wps/wcm/connect/rosstat_main/ rosstat/ru/statistics/publications/catalog/doc_1140095700094.

\section{References}

1. Zdorov'e-2020: osnovy evropejskoj politiki i strategija dlja $X X$ veka. Dostupno po ssylke: www.euro.who.int/_data/assets/ pdf_file/0017/215432/Health2020-Long-Rus.pdf.

2. Bojcov SA, Chuchalin AG, redaktory. Profilaktika hronicheskih neinfekcionnyh zabolevanij. Rekomendacii. M., 2013; 136.

3. WHO Scientific Group. Burden of musculoskeletal conditions at the start of the new millennium. Technical Report Series. Genove, Switzerland: World Health Organization; 2003: 1-218. Available from: http://www.who.int/iris/handle/10665/ 42721

4. EUMUSC.NET. Musculoskeletal Health in Europe. Available from: http://www.eumusc.net/myUploadData/files/30\%20August\%20 Final\%20draft\%20report.pdf [accessed 10 April 2016].

5. Mazurov VI, Lesnjak OM, redaktory. Osteoartrit. Revmatologija Farmakoterapija bez oshibok: rukovodstvo dlja vrachej. M.: E-noto, 2017; c. 51-78.

6. Nikolaev JuA, Mitrofanov IM, Poljakov VJa i dr. Arterial'naja gipertenzija, svjazannaja $\mathrm{S}$ somaticheskoj patologiej, $\mathrm{v}$ sovremennoj praktike vnutrennih zabolevanij. Zdorov'e. 2014; 6 (1): 94-8.

7. Zdravoohranenie v Rossii. 2017: Statisticheskij sbornik Rosstat M., 2017; 170 .

8. Shljafer SI. Ocenka sostojanija zdorov'ja sel'skogo naselenija starshe trudosposobnogo vozrasta $\vee$ Rossijskoj Federacii.

10. Hagen K, Linde M, Heuch I, Stovner LJ, Zwart JA. Increasing prevalence of chronic musculoskeletal complaints: a large 11-year follow-up in the general population (HUNT 2 and 3). Pain Med. 2011; 12 (11): 1657-66. DOl:10.1111/j.1526-4637.2011.01240.x.

11. Антипова С. И., Валькевич В. П., Антипов В. В., Савина И. И. Болезни костно-мышечной системы и соединительной ткани в Беларуси - проблема здоровья и качества жизни. Медицинские новости. 2013; (5): 50-55.

12. Киченко А. А., Тверье В. М., Няшин Ю. И., Заборских А. А. Экспериментальное определение тензора структурь трабекулярной костной ткани. Российский журнал биомеханики. 2011; 4 (54): 78-93.

13. Острая неспецифическая боль в спине. Руководство для врачей общей практики (семейных врачей). 2015; 15 с. Доступно по ссылке: http://democenter.nitrosbase.com/ clinrecalg5/Files/recomend/\%D0\%92\%D0\%9E\%D0\%9F30.PDF.

14. Каратеев А. Е., Насонов Е. Л. Применение нестероидных противовоспалительных препаратов при ревматических заболеваниях. В книге: Насонов Е. Л., редактор. Российские клинические рекомендации. Ревматология. М.: ГЭОТАРМедиа, 2017; с. 339-59.

15. Коморбидная патология В клинической практике. Клинические рекомендации. Общероссийская общественная организация Ассоциация врачей общей практики (семейных врачей). Секция «Сочетанные патологии». Кардиоваскулярная терапия и профилактика. 2017; 16 (6): 37-39. Доступно по ссылке: http://dx.doi.org/10.15829/1728-8800-2017-6-5-56.

16. Parreira P1, Heymans MW, van Tulder MW, Esmail R, Koes BW, Poquet $N$, et al. Back Schools for chronic non-specific low back pain. Cochrane Database Syst Rev. 2017; Aug 3; 8. DOI: 10.1002/14651858.CD011674.pub2.

Problemy social'noj gigieny, zdravoohranenija i istorii mediciny. 2014; (5): 13-19.

9. Chislennost' naselenija Rossijskoj Federacii po polu i vozrastu na 1 janvarja 2017 g. Bjulleten'. Dostupno po ssylke: http://www. gks.ru/wps/wcm/connect/rosstat_main/rosstat/ru/statistics/ publications/catalog/doc_1140095700094.

10. Hagen K, Linde M, Heuch I, Stovner LJ, Zwart JA. Increasing prevalence of chronic musculoskeletal complaints: a large 11-year follow-up in the general population (HUNT 2 and 3). Pain Med. 2011; 12 (11): 1657-66. DOl:10.1111/j.15264637.2011.01240.x

11. Antipova SI, Valkevich VP, Antipov W, Savina II. Bolezni kostnomyshechnoj sistemy i soedinitel'noj tkani v Belarusi — problema zdorov'ja i kachestva zhizni. Medicinskie novosti. 2013; (5): 50-55.

12. Kichenko AA, Tver'e VM, Njashin Jul, Zaborskih AA. Jeksperimental'noe opredelenie tenzora struktury trabekuljarnoj kostnoj tkani. Rossijskij zhurnal biomehaniki. 2011; 4 (54): 78-93.

13. Ostraja nespecificheskaja bol' v spine. Rukovodstvo dlja vrachej obshhej praktiki (semejnyh vrachej). 2015, 15 s. Dostupno po ssylke: http://democenter.nitrosbase.com/clinrecalg5/Files/ recomend/\%D0\%92\%D0\%9E\%D0\%9F30.PDF.

14. Karateev AE, Nasonov EL. Primenenie nesteroidnyh protivovospalitel'nyh preparatov pri revmaticheskih zabolevanijah. 
$\checkmark$ knige: Nasonov EL, redaktor. Rossijskie klinicheskie rekomendacii. Revmatologija. M.: GJeOTAR-Media, 2017; s. 339-59.

15. Komorbidnaja patologija $\vee$ klinicheskoj praktike. Klinicheskie rekomendacii. Obshherossijskaja obshhestvennaja organizacija Associacija vrachej obshhej praktiki (semejnyh vrachej). Sekcija «Sochetannye patologii». Kardiovaskuljarnaja terapija i profilaktika. 2017; 16 (6): 37-39. Dostupno po ssylke: http:// dx.doi.org/10.15829/1728-8800-2017-6-5-56.

16. Parreira P1, Heymans MW, van Tulder MW, Esmail R, Koes BW, Poquet N, et al. Back Schools for chronic non-specific low back pain. Cochrane Database Syst Rev. 2017; Aug 3; 8. DOI: 10.1002/14651858.CD011674.pub2. 